\title{
Higher Rate of Patellofemoral Problems After Anterior Cruciate Ligament Reconstruction using Hamstring Autograft
}

\author{
Krisna Yuarno Phatama*(D), Romy Darmawansa ${ }^{1}$ D, I Gusti Ngurah Arga Aldrian Oktafandi ${ }^{1}$, Felix Cendikiawan ${ }^{1}$ (D) \\ Alva Pribadi ${ }^{1}$, Lasa Dhakka Siahaan ${ }^{1}$ (D) , Sholahuddin Rhatomy ${ }^{3}$ (D) Edi Mustamsir $^{1}$ (D) \\ ${ }^{1}$ Department of Orthopaedics and Traumatology, Faculty of Medicine, Universitas Brawijaya, RSUD Dr. Saiful Anwar, Malang, \\ East Java, Indonesia; ${ }^{2}$ Department of Orthopaedics and Traumatology, RSUD Dr. H. Andi Abdurrahman Noor, Tanah Bumbu, \\ South Borneo, Indonesia; ${ }^{3}$ Department of Orthopaedics and Traumatology, Faculty of Medicine, Public Health and Nursing \\ Universitas Gadjah Mada, RSUP Dr. Soeradji Tirtonegoro, Klaten, Central Java, Indonesia
}

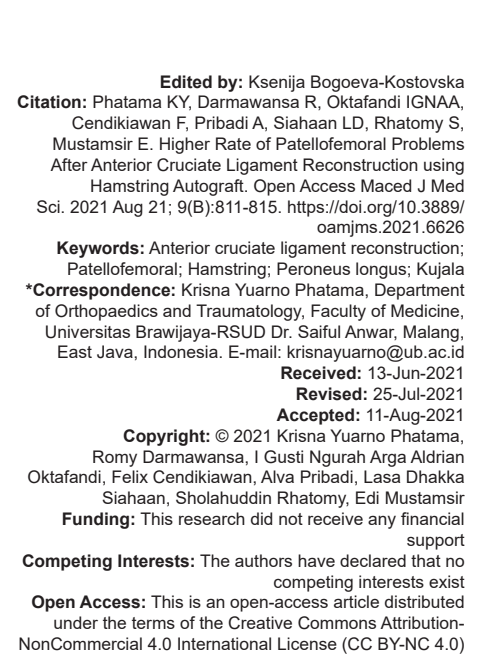

\section{Abstract}

BACKGROUND: Patellofemoral problems are not uncommon among post-anterior cruciate ligament (ACL) reconstruction patients. Hamstring autograft harvesting-related factor is one of the suspected causes. A lack of tibiofemoral internal rotation force due to strength deficit causes the patella tends to shift laterally.

AIM: Peroneus longus tendon has been proposed as an alternative graft source due to its adequate tensile strength and minimal donor site morbidity to the knee biomechanics, including the patellofemoral joint. This tendon does not cross the knee joint and thus does not affect patellofemoral alignment and biomechanics. This study aims to compare patellofemoral problems between hamstring and peroneus longus autograft harvested patients following ACL reconstruction.

MATERIALS AND METHODS: Thirty-one subjects who underwent primary single-bundle ACL reconstruction between September 2018 and September 2019 and met the inclusion criteria were grouped into the hamstring group $(n=16)$ and peroneus longus group $(n=15)$. Both groups were evaluated retrospectively. The follow-up assessment was conducted on the phase II rehabilitation program. The assessed variables were pain, crepitus, and the Indonesian-validated Kujala score.

RESULTS: No significant differences in pain and crepitus were found between both groups. There were significan differences in the Kujala score between both groups $(p<0.001)$. The peroneus longus group reported an averagely higher score than the hamstring group.

CONCLUSION: Single bundle ACL reconstruction using peroneus longus tendon autograft produces less patellofemoral symptoms and functional limitation than using hamstring tendon autograft.

\section{Introduction}

Anterior cruciate ligament $(A C L)$ injury is one of the most common injuries found in orthopedic sports clinics. The incidence is one in 3000 people each year in the United States, and 100.000-300.000 ACL reconstructions are performed annually [1], [2] ACL reconstruction aims to restore knee stability, allow returning to sports, prevent meniscal tears, and possibly prevent early-onset osteoarthritis of the knee [3]. The technique, graft sources, and devices used in ACL reconstruction have been studied extensively to find the best option for the patient. Nevertheless, one unsolved complication following $A C L$ reconstruction is patellofemoral problems.

Patellofemoral problems, such as patellofemoral pain, have been reported to occur in post ACL reconstruction knee [4], [5], [6], [7]. The highest incidence of patellofemoral pain has been found in
$A C L$ reconstruction using bone-patellar tendon-bone (BPTP) autograft, which has been the standard source of graft [8]. Therefore, hamstring tendon autograft has gained popularity as an alternative source of graft. Although some studies reported a significantly lower incidence of patellofemoral pain in ACL reconstructed patients with hamstring tendon autograft than BPTP autograft, it does not necessarily mean that the use of hamstring tendon autograft is spared from patellofemoral pain [5], [9], [10], [11]. Culvenor et al. [5] reported that $30 \%$ of patients had patellofemoral pain after hamstring tendon $\mathrm{ACL}$ reconstruction. Hamstring autograft harvesting-related factor is one of the suspected causes. A lack of a tibiofemoral internal rotation force due to decreased hamstring strength causes the patella to shift laterally and has been proposed to elucidate this problem [12], [13], [14]. However, the exact mechanism behind it is still unclear.

This problem encourages researchers to look for another alternative graft source, and the peroneus longus tendon has been investigated extensively for this 
purpose. Some studies discovered that the peroneus longus tendon has adequate tensile strength and minimal donor site morbidity to the knee biomechanics, including the patellofemoral joint [15], [16], [17], [18]. The proposed reason is that the peroneus longus tendon does not cross the knee joint so that its harvest does not affect patellofemoral alignment and biomechanics. This study aims to compare the patellofemoral symptoms and functional scores between hamstring and peroneus longus harvested patients following ACL reconstruction.

\section{Materials and Methods}

\section{Study design and subject selection}

This study is a retrospective cohort study with consecutive sampling. Patients aged $16-45$ years old with isolated $A C L$ rupture, underwent primary single-bundle ACL reconstruction either with hamstring tendon or ipsilateral peroneus longus tendon autografts between September 2018 and September 2019 and participated in the phase II rehabilitation program for follow up were eligible for inclusion. The diagnosis of isolated ACL rupture was established based on anamnesis, physical examination, and magnetic resonance imaging of the injured knee. We excluded ACL revision cases, ACL rupture with concomitant injury (multi-ligament injury, cartilage defect, meniscal injury, fracture around the knee), pathologic condition on the lower extremity, and abnormal contralateral knee joint. Accordingly, 31 patients were available for evaluation and divided into two groups (16 hamstring tendon autograft, 15 peroneus longus autograft). Ethical approval was granted by the ethical committee at the designated hospital, and subjects provided written informed consent before participation. This study has been carried out in line with The Code of Ethics of the World Medical Association (Declaration of Helsinki) for experiments involving humans [19].

\section{Arthroscopic procedure}

A single knee surgeon performed all the arthroscopic procedure. The patients lay in a supine position under regional anesthesia, and a tourniquet was applied to the thigh and inflated without elevation and exsanguination. Standard anterolateral and anteromedial portals were used. Diagnostic arthroscopy for ACL rupture was initially performed, followed by graft harvesting of either the ipsilateral peroneus longus or the hamstring tendon (semitendinosus and gracilis tendons). For the peroneus tendon, the skin incision location was marked $2-3 \mathrm{~cm}$ above and $1 \mathrm{~cm}$ behind the lateral malleolus. The incision was then made through the skin, subcutaneous tissue, and superficial fascia. The peroneus longus and peroneus brevis tendons were located $2-3 \mathrm{~cm}$ above the lateral malleolus level. The distal part of the peroneus longus tendon was sutured to the peroneus brevis tendon with end-to-side sutures. The peroneus longus tendon was then stripped proximally with a tendon stripper to about $4-5 \mathrm{~cm}$ from the fibular head to prevent peroneal nerve injury.

The intercondylar notch was then cleared of fibrous tissue to ease visualization during the tunnels' preparation, but some remaining $A C L$ fibers were preserved as a reference for tunnel placement. The femoral tunnel and the tibial tunnel were then prepared independently. After drilling the tunnels, we proceeded with the implantation of the tendon with graft fixation on the femoral side with a button (XO Button ${ }^{\circledR}$, Conmed $^{\odot}$, USA) and graft fixation on the tibial side with a bioabsorbable screw $\left(\right.$ Bioscrew $^{\circledR}$, Conmed $^{\circledR}$, USA) after appropriate tensioning with a graft tensioner.

\section{Rehabilitation and follow up assessment}

Both groups of patients were treated with the same rehabilitation program that was divided into five phases.

- $\quad$ Phase I (week 1-2): partial weight-bearing and full extension within 14 days

- $\quad$ Phase II (week 3-6): quadriceps and hamstring strengthening

- $\quad$ Phase III (week 6-12): proprioceptive exercise - $\quad$ Phase IV (week 12-20): early sport activity - $\quad$ Phase V (week 20-24): return to sport.

The follow-up assessment was conducted on the phase II rehabilitation program to give the surgical wound enough time to recover. The assessment was performed by anamnesis and physical examination for the presence of pain and crepitus. Both pain and crepitus were reported as yes (present) or no (not present). Subsequently, both groups were asked to fill the Indonesian version of the Kujala Anterior Knee Pain Scale or shortly known as the Kujala score, a patientreported evaluation of patellofemoral pathology based on symptoms and functional limitation, and comprised of 13 questions [20]. The responses were summed to obtain a total score of $0-100$, with 100 means no pain or limitation. The Indonesian version of the Kujala score's validity and reliability to assess patellofemoral pain have been reported [21].

\section{Statistical analysis}

The comparison of age, weight, height, time from surgery to evaluation, and Kujala score between hamstring and peroneus longus groups were performed using either the Mann-Whitney $U$ test or independent sample t-test, depending on the data distribution. Fisher's exact test was conducted to compare the gender and the presence of pain and crepitus between hamstring and peroneus longus groups. All analysis 
was executed with IBM SPSS Statistics 25 for Windows. A $p<0.05$ was accepted as statistically significant.

\section{Results}

Of 31 subjects, $21(68 \%)$ are males, and $10(32 \%)$ are females. The characteristics of the subjects are presented in Table 1. Sixteen (52\%) subjects had surgery with hamstring tendon autograft and $15(48 \%)$ subjects with peroneus longus tendon autograft. There were no significant differences in age, gender, weight, height, and time from surgery to evaluation between both groups.

Table 1: Characteristics of the study population

\begin{tabular}{llll}
\hline Variables & Hamstring group $(\mathrm{n}=16)$ & Peroneus longus group $(\mathrm{n}=15)$ & $\mathrm{p}$-value \\
\hline Age (years) & $23.19(16-38)$ & $24.20(16-49)$ & 0.890 \\
Gender & Male: 10 & Male: 11 & 0.704 \\
& Female: 6 & Female: 4 & \\
Weight $(\mathrm{kg})$ & $63.81(47-90)$ & $72.33(50-97)$ & 0.113 \\
Height $(\mathrm{cm})$ & $168.38(149-185)$ & $168.53(152-195)$ & 0.751 \\
Time from & $6.72(2-12)$ & $8.87(4-12)$ & 0.173 \\
surgery to follow & & & \\
up (months) & & & \\
\hline
\end{tabular}

Table 2 Compared the assessment results on pain, crepitus, and Kujala score between hamstring and peroneus longus groups. There were no significant differences in pain $(p=0.433)$ and crepitus $(p=0.716)$ between both groups. However, significant differences in the Kujala score were noted between both groups $(p<0.001)$. The peroneus longus group reported an averagely higher score than the hamstring group.

Table 2: Comparison of the assessment outcome

\begin{tabular}{llll}
\hline Variables & Hamstring group $(n=16)$ & Peroneus longus group $(n=15)$ & $p$-value \\
\hline Pain & Yes: 6 & Yes: 3 & 0.433 \\
& No: 10 & No: 12 & \\
Crepitus & Yes: 9 & Yes: 10 & 0.716 \\
& No: 7 & No: 5 & \\
Kujala score & 71.44 (SD 10.89) & 93.53 (SD 5.84) & $<0.001$ \\
\hline
\end{tabular}

\section{Discussion}

The use of BPTB autograft for ACL reconstruction has been held accountable for postsurgery patellofemoral complications [10], [22], [23]. Nonetheless, these complications still occurred in patients after $\mathrm{ACL}$ reconstruction using hamstring tendon, although the number was not as high as BPTB harvested patients [5], [24]. For this reason, studies have investigated peroneus longus tendon as the alternative graft source for ACL reconstruction.

This study found significant differences in Kujala score between the hamstring and peroneus longus groups favoring the peroneus longus group $(p<0.001)$. The mean Kujala score for the hamstring and peroneus longus groups was 71.44 (SD 10.89) and 93.53 (SD 5.84), respectively. The Kujala score has been proven to be valid and reliable for the diagnosis and screening of patellofemoral disorders [25], [26]. From our result, it can be concluded that the peroneus longus group had fewer patellofemoral symptoms and functional limitations than the hamstring group. Kujala et al. [20] reported that a low Kujala score is correlated with increased lateral patellar tilt during quadriceps contraction in $0^{\circ}$ knee flexion, and this lateral tilt may be the cause of patellofemoral pain.

To the best of our knowledge, this is the first study that compares the patellofemoral disorders between hamstring and peroneus longus harvested patients with the Kujala score. Therefore, no studies can be used as a direct comparison to our study. Nevertheless, several studies have investigated the knee's functional status in the hamstring and peroneus longus groups using different methods. Rhatomy et al. [17] reported that $A C L$ reconstruction using peroneus longus had comparable knee functional score to the hamstring as calculated with the International Knee Documentation Committee (IKDC) Subjective Knee Form, modified Cincinnati score, and Lysholm score. These findings are consistent with the results by Shi et al., [18] who found comparable functional scores, evaluated with Tegner-Lysholm Knee Scoring Scale and IKDC, between peroneus longus and hamstring groups. These two studies have a contrasting result with our study in terms of the functional scores. If we set aside the different scoring systems used, the follow-up time and the graft folding may elucidate this contrasting result. Decreased hamstring strength and loss of flexion range of motion (ROM) have been proposed as the cause of patellofemoral pain in hamstring harvested patients [13]. Whereas, rehabilitation post $\mathrm{ACL}$ reconstruction has proven to strengthen the hamstring and regain the flexion ROM, thus decreasing the patellofemoral pain [27], [28]. Rhatomy et al. [17] evaluated their subjects 1 year after surgery, giving the patients time to complete the rehabilitation and possibly lessen the patellofemoral symptoms. Meanwhile, Shi et al. [18] performed the reconstruction using doubled peroneus longus autograft and quadrupled hamstring autograft, instead of single bundled autografts like in our study. In their study, Shi et al. [18] reported that doubled peroneus longus and quadrupled hamstring had a comparable tensile strength. Therefore, it may be concluded that a single bundle hamstring graft has a lower tensile strength than a single bundle peroneus longus graft. The lower tensile strength in the hamstring tendon possibly causes patellofemoral problems and thus lower the Kujala score. However, further investigation is needed to confirm this possibility.

Although we found significant differences in the Kujala score, we discovered no significant pain and crepitus differences between both groups. Nevertheless, anamnesis and physical examination were conducted to assess persistent pain and crepitus present at the moment of the examination. Therefore, 
the results could not represent the presence of pain and crepitus during various activities. Moreover, the Kujala score consists of seven pain-related activities questions, four pain-unrelated questions, and only two questions that evaluated persistent pain.

This study has some limitations. First, the lower incidence of isolated $A C L$ rupture than $A C L$ rupture with concomitant injuries resulted in our study's small sample population. We wanted to make sure that our study has as few biasing factors as possible by excluding other cases besides isolated ACL rupture. Second, since we did not have pre-surgery data of pain, crepitus, and Kujala score, we could not compare it with our post-surgery results. Thus, the possibility of preexisting patellofemoral disorders could not be investigated. Finally, we only conduct one follow-up evaluation of our subjects because the number of rehabilitation participants in our hospital tends to decrease after phase II, resulting in the loss of follow-up. Nonetheless, this is the first study that compares the patellofemoral functional status between hamstring and peroneus longus autografts using the Kujala score. Further investigations with larger sample sizes, more parameters, and longer follow-up will add more knowledge regarding this matter.

\section{Conclusions}

Single bundle ACL reconstruction using peroneus longus tendon autograft produces less patellofemoral symptoms and functional limitation than using hamstring tendon autograft.

\section{Ethical Approval}

This study has been reviewed and approved by the Medical and Health Research Ethics Committee No: KE/FK/1396/EC/2020.

\section{References}

1. Baer GS, Harner CD. Clinical outcomes of allograft versus autograft in anterior cruciate ligament reconstruction. Clin Sports Med. 2007;26(4):661-81. https://doi.org/10.1016/j. csm.2007.06.010 PMid:17920959

2. Cohen SB, Yucha DT, Ciccotti MC, Goldstein DT, Ciccotti MA, Ciccotti MG. Factors affecting patient selection of graft type in anterior cruciate ligament reconstruction. Arthrosc J Arthrosc Relat Surg. 2009;25(9):1006-10. https://doi.org/10.1016/j. arthro.2009.02.010

PMid:19732639

3. Chee MY, Chen Y, Pearce CJ, Murphy DP, Krishna L, Hui $\mathrm{JH}$, et al. Outcome of patellar tendon versus 4-strand hamstring tendon autografts for anterior cruciate ligament reconstruction: A systematic review and meta-analysis of prospective randomized trials. Arthrosc J Arthrosc Relat Surg. 2017;33(2):450-63. https://doi.org/10.1016/j.arthro.2016.09.020 PMid:28040335

4. Aglietti P, Buzzi R, D’Andria S, Zaccherotti G. Patellofemoral problems after intraarticular anterior cruciate ligament reconstruction. Clin Orthop Relat Res. 1993;288:195-204. https://doi.org/10.1097/00003086-199303000-00025

PMid:8458134

5. Culvenor AG, Collins NJ, Vicenzino B, Cook JL, Whitehead TS, Morris HG, et al. Predictors and effects of patellofemoral pain following hamstring-tendon ACL reconstruction. J Sci Med Sport. 2015;19(7):518-23. https://doi.org/10.1016/j.jsams.2015.07.008 PMid:26205774

6. Culvenor AG, Lai CC, Gabbe BJ, Makdissi M, Collins NJ, Vicenzino $B$, et al. Patellofemoral osteoarthritis is prevalent and associated with worse symptoms and function after hamstring tendon autograft $\mathrm{ACL}$ reconstruction. $\mathrm{Br} \mathrm{J}$ Sports Med. 2013;48(6):435-9. https://doi.org/10.1136/bjsports-2013-092975

7. Sachs RA, Daniel DM, Stone ML, Garfein RF. Patellofemora problems after anterior cruciate ligament reconstruction. Am J Sports Med. 1989;17(6):760-5. https://doi. org/10.1177/036354658901700606 PMid:2624287

8. Xie X, Liu X, Chen Z, Yu Y, Peng S, Li Q. A meta-analysis of bone-patellar tendon-bone autograft versus four-strand hamstring tendon autograft for anterior cruciate ligament reconstruction. Knee. 2015;22(2):100-10. https://doi. org/10.1016/j.knee.2014.11.014

PMid:25547048

9. Eriksson K, Anderberg P, Hamberg P, Olerud P, Wredmark T. There are differences in early morbidity after $\mathrm{ACL}$ reconstruction when comparing patellar tendon and semitendinosus tendon graft. A prospective randomized study of 107 patients. Scand J Med Sci Sports. 2001;11(3):170-7. https://doi. org/10.1046/j.1524-4725.2001.110307.x

PMid:11374431

10. Ibrahim SA, Al-Kussary IM, Al-Misfer AR, Al-Mutairi HQ, Ghafar SA, EI Noor TA. Clinical evaluation of arthroscopically assisted anterior cruciate ligament reconstruction: Patellar tendon versus gracilis and semitendinosus autograft. Arthroscopy. 2005;21(4):412-7. https://doi.org/10.1016/j. arthro.2004.12.002 PMid: 15800520

11. Shaieb MD, Kan DM, Chang SK, Marumoto JM, Richardson AB A prospective randomized comparison of patellar tendon versus semitendinosus and gracilis tendon autografts for anterior cruciate ligament reconstruction. Am J Sports Med. 2002;30(2):214-20. https://doi.org/10.1177/0363546502030002 1201

PMid:11912091

12. Giotis D, Paschos NK, Zampeli F, Pappas E, Mitsionis G, Georgoulis AD. Bracing can partially limit tibial rotation during stressful activities after anterior crucial ligament reconstruction with a hamstring graft. Orthop Traumatol Surg Res. 2016;102(5):601-6. https://doi.org/10.1016/j.otsr.2016.04.005 PMid:27234872

13. Nakamura N, Horibe $S$, Sasaki $S$, Kitaguchi T, Tagami M, Mitsuoka T, et al. Evaluation of active knee flexion and hamstring strength after anterior cruciate ligament reconstruction 
using hamstring tendons. Arthrosc $\mathrm{J}$ Arthrosc Relat Surg. 2002;18(6):598-602. https://doi.org/10.1053/jars.2002.32868 PMid:12098120

14. Torry MR, DeckerMJ, Jockel JR, ViolaR, SterettWI, Steadman JR. Comparison of tibial rotation strength in patients' status after anterior cruciate ligament reconstruction with hamstring versus patellar tendon autografts. Clin J Sport Med. 2004;14(6):325-31. https://doi.org/10.1097/00042752-200411000-00001 PMid:15523203

15. Bi M, Zhao C, Zhang S, Yao B, Hong Z, Bi Q. All-inside singlebundle reconstruction of the anterior cruciate ligament with the anterior half of the peroneus longus tendon compared to the semitendinosus tendon: A two-year follow-up study. J Knee Surg. 2018;31(10):1022-30. https://doi.org/10.1055/s-0038-1627466 PMid:29421837

16. Phatama KY, Hidayat M, Mustamsir E, Pradana AS, Dhananjaya B, Muhammad SI. Tensile strength comparison between hamstring tendon, patellar tendon, quadriceps tendon and peroneus longus tendon: A cadaver research. J Arthrosc Joint Surg. 2019;6(2):114-6. https://doi.org/10.1016/j. jajs.2019.02.003

17. Rhatomy $\mathrm{S}$, Asikin Al, Wardani AE, Rukmoyo T, LumbanGaol I, Budhiparama NC. Peroneus longus autograft can be recommended as a superior graft to hamstring tendon in single-bundle ACL reconstruction. Knee Surg Sport Traumatol Arthrosc. 2019;27(11):3552-9. https://doi.org/10.1007/ s00167-019-05455-w PMid:30877316

18. Shi F-D, Hess DE, Zuo JZ, Liu SJ, Wang XC, Zhang Y, et al. Peroneus longus tendon autograft is a safe and effective alternative for anterior cruciate ligament reconstruction. J Knee Surg. 2019;32(8):804-11. https://doi. org/10.1055/s-0038-1669951

\section{PMid:30206913}

19. Association WM. World medical association declaration of Helsinki: Ethical principles for medical research involving human subjects. JAMA. 2013;310(20):2191-4. https://doi.org/10.1001/ jama.2013.281053

PMid:24141714

20. Kujala UM, Jaakkola LH, Koskinen SK, Taimela S, Hurme M, Nelimarkka O. Scoring of patellofemoral disorders. Arthrosc $J$ Arthrosc Relat Surg. 1993;9(2):159-63. https://doi.org/10.1037/ t35846-000

\section{PMid:8461073}

21. Mustamsir E, Phatama KY, Pratianto A, Pradana AS, Sukmajaya WP, Pandiangan RA, et al. Validity and reliability of the indonesian version of the kujala score for patients with patellofemoral pain syndrome. Orthop J Sport Med. 2020;8(5):15. https://doi.org/10.1177/2325967120922943 PMid:32523969

22. Boszotta H, Prünner K. Refilling of removal defects: Impact on extensor mechanism complaints after use of a bonetendon-bone graft for anterior cruciate ligament reconstruction. Arthrosc J Arthrosc Relat Surg. 2000;16(2):160-4. https://doi. org/10.1016/s0749-8063(00)90030-6

PMid: 10705327

23. Li S, Su W, Zhao J, Xu Y, Bo Z, Ding X, et al. A metaanalysis of hamstring autografts versus bone-patellar tendonbone autografts for reconstruction of the anterior cruciate ligament. Knee. 2011;18(5):287-293. https://doi.org/10.1016/j. knee.2010.08.002

PMid:20850327

24. Lee DW, Yeom CH, Kim DH, Kim TM, Kim JG. Prevalence and predictors of patellofemoral osteoarthritis after anterior cruciate ligament reconstruction with hamstring tendon autograft. Clin Orthop Surg. 2018;10(2):181. https://doi.org/10.4055/ cios.2018.10.2.181

PMid:29854341

25. Bennell K, Bartam S, Crossley K, Green S. Outcome measures in patellofemoral pain syndrome: Test retest reliability and interrelationships. Phys Ther Sport. 2000;1(2):32-41. https://doi. org/10.1054/ptsp.2000.0009

26. Crossley KM, Bennell KL, Cowan SM, Green S. Analysis of outcome measures for persons with patellofemoral pain: Which are reliableand valid?Arch Phys Med Rehabil. 2004;85(5):815-22. https://doi.org/10.1016/s0003-9993(03)00613-0

PMid:15129407

27. Shelbourne KD, Nitz P. Accelerated rehabilitation after anterior cruciate ligament reconstruction. Am J Sports Med. 1990;18(3):292-9. https://doi.org/10.1177/036354659001800313 PMid:2372081

28. Shelbourne KD, Trumper RV. Preventing anterior knee pain after anterior cruciate ligament reconstruction. Am J Sports Med. 1997;25(1):41-7. https://doi.org/10.1177/036354659702500108 PMid:9006690 